\title{
Increased Leishmania infantum resistance to miltefosine and amphotericin $B$ after treatment of a dog with miltefosine and allopurinol
}

\author{
Gustavo Gonçalves ${ }^{*}$ (D), Monique Paiva Campos', Alessandra Silva Gonçalves², \\ Lia Carolina Soares Medeiros ${ }^{1}$ and Fabiano Borges Figueiredo ${ }^{1}$
}

\begin{abstract}
Background: Leishmania infantum is the most important etiological agent of visceral leishmaniasis in the Americas and Mediterranean region, and the dog is the main host. Miltefosine was authorized to treat canine leishmaniasis (CanL) in Brazil in 2017, but there is a persistent fear of the emergence of parasites resistant not only to this drug but, through cross-resistance mechanisms, also to meglumine antimoniate and amphotericin B. Additionally, the literature shows that acquisition of resistance is followed by increased parasite fitness, with higher rates of proliferation, infectivity and metacyclogenesis, which are drivers of parasite virulence. In this context, the aim of this study was to analyze the impact of treating a dog with miltefosine and allopurinol on the generation of parasites resistant to miltefosine, amphotericin B and meglumine antimoniate.
\end{abstract}

Methods: In vitro susceptibility tests were conducted against miltefosine, amphotericin B and meglumine antimoniate with T0 (parasites isolated from a dog before treatment with miltefosine plus allopurinol), T1 (after 1 course of treatment) and T2 (after 2 courses of treatment) isolates. The rates of cell proliferation, infectivity and metacyclogenesis of the isolates were also evaluated.

Results: The results indicate a gradual increase in parasite resistance to miltefosine and amphotericin B with increasing the number of treatment courses. An increasing trend in the metacyclogenesis rate of the parasites was also observed as drug resistance increased.

Conclusion: The data indicates an increased $L$. infantum resistance to miltefosine and amphotericin $B$ after the treatment of a dog with miltefosine plus allopurinol. Further studies with a larger number of $L$. infantum strains isolated from dogs with varied immune response profiles and undergoing different treatment regimes, are advocated.

Keywords: Amastigote, Clinical isolate, In vitro test, Promastigote

*Correspondence: gustavogonsalves@live.com

${ }^{1}$ Cell Biology Laboratory, Carlos Chagas Institute, Oswaldo Cruz Foundation (FIOCRUZ), Curitiba, Paraná 81310-020, Brazil

Full list of author information is available at the end of the article

(c) The Author(s) 2021. Open Access This article is licensed under a Creative Commons Attribution 4.0 International License, which permits use, sharing, adaptation, distribution and reproduction in any medium or format, as long as you give appropriate credit to the original author(s) and the source, provide a link to the Creative Commons licence, and indicate if changes were made. The images or other third party material in this article are included in the article's Creative Commons licence, unless indicated otherwise in a credit line to the material. If material is not included in the article's Creative Commons licence and your intended use is not permitted by statutory regulation or exceeds the permitted use, you will need to obtain permission directly from the copyright holder. To view a copy of this licence, visit http://creativecommons.org/licenses/by/4.0/. The Creative Commons Public Domain Dedication waiver (http://creativeco mmons.org/publicdomain/zero/1.0/) applies to the data made available in this article, unless otherwise stated in a credit line to the data. 


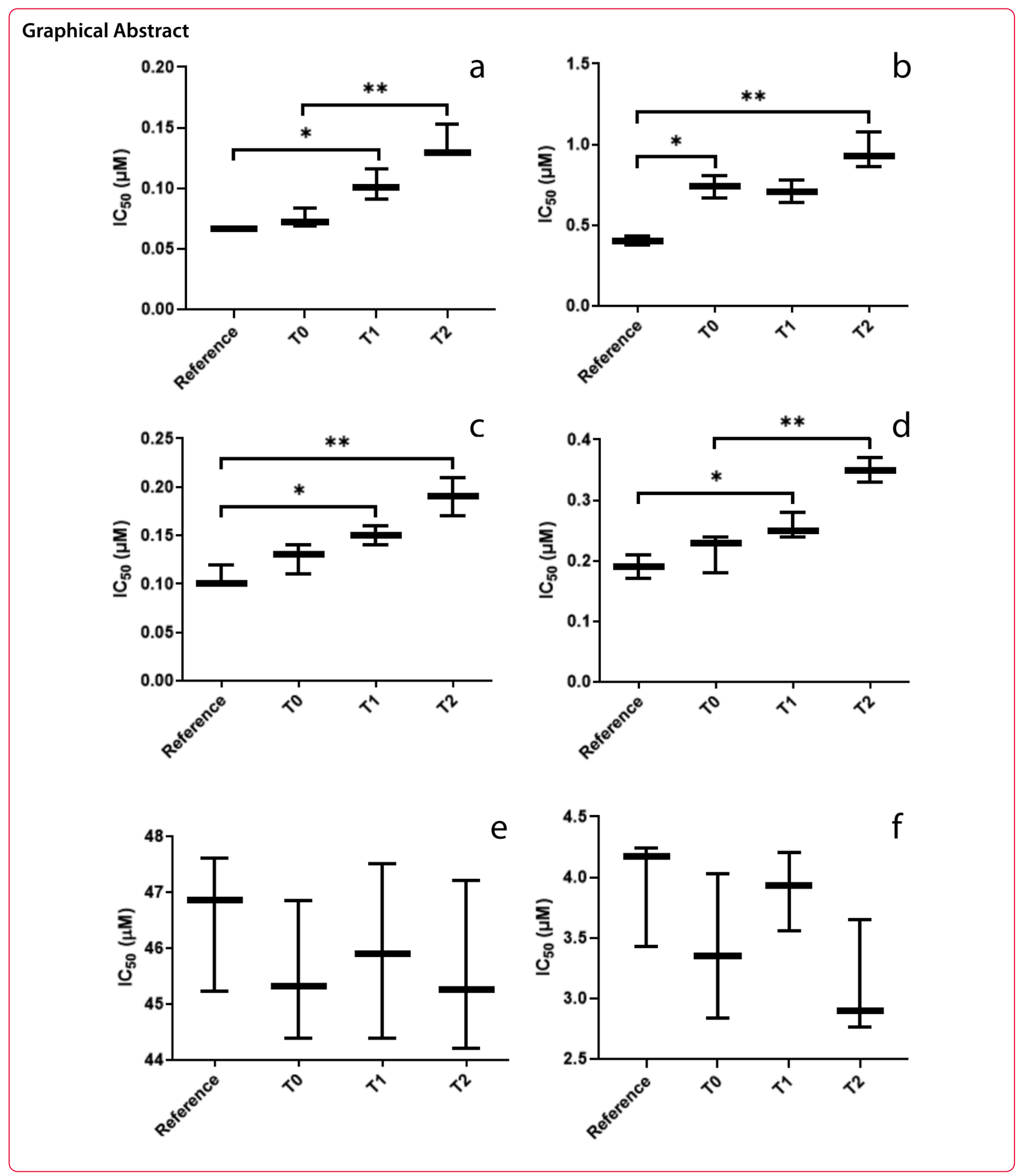

Leishmania infantum is the most important etiological agent of visceral leishmaniasis (VL) in the Americas and the Mediterranean region [1], and the dog is the main host [2]. Canine leishmaniasis (CanL) usually precedes the occurrence of human cases [2], and control of the zoonotic cycle remains a challenge [3].

In 2017, Brazilian regulatory agencies authorized the use of miltefosine to treat canine leishmaniasis (CanL) in Brazil [4], and it remains the only treatment for CanL 
currently available in the country. Despite therapeutic success in most cases [5], treatment failures have been observed in both monotherapy and combined therapies [6], with improvement in canine clinical signs not always followed by parasite clearance [7]. Thus, miltefosine treatment is still not considered a fully effective control measure because in addition to the risk of parasite resistance, relapses are reported and dogs can continue to infect the invertebrate host even weeks after the end of treatment, despite being clinically cured [8]. For this reason, a fundamental part of CanL treatment is to use insecticide-impregnated collars on dogs undergoing treatment.

In addition to the treatment of dogs with miltefosine being associated with the possible emergence of parasites resistant to this drug, some in vitro studies have shown cross-resistance to other drugs $[9,10]$ that can lead to the emergence of parasites resistant not only to miltefosine, but also to other drugs used to treat VL. Moreover, there are also reports on the impact of acquisition of resistance on parasite fitness, in which drug-resistant parasites presented higher rates of cell proliferation, metacyclogenesis and infectivity compared with those of susceptible parasites [11-13], which are aggravating factors of disease virulence [14].

In this context, the aim of the present study was to analyze the impact of treating a dog with CanL with miltefosine plus allopurinol on the generation of parasites resistant to miltefosine, amphotericin $\mathrm{B}$ and meglumine antimoniate. A secondary aim was to determine the impact of the possible acquisition of resistance on the rates of cell proliferation, metacyclogenesis and infectivity of the parasite.

The isolates used in this study were obtained from a naturally infected, mixed-breed female dog, aged approximately 5 years, from the municipality of Campo Grande, state of Mato Grosso do Sul, Brazil. After positive serological diagnosis using the Dual-path Platform chromatographic immunoassay $\left(\mathrm{DPP}^{\circledR}\right)$, additional collections were performed to confirm the infection by $L$. infantum through quantitative PCR (qPCR) and parasitological culture. For the qPCR, a 3-mm-diameter intact skin fragment of the dog was obtained by punch biopsy (scapular region) and stored in a sterile flask free of RNase and DNase at $-20^{\circ} \mathrm{C}$. For the parasitological culture, another skin fragment as well as bone marrow and lymph node aspirates were collected and stored in sterile saline solution containing antibiotics and antifungals under refrigeration. The samples were kept at $4{ }^{\circ} \mathrm{C}$ for $24 \mathrm{~h}$, then sown in biphasic culture medium containing Novy-MacNeal-Nicole medium and Schneider's insect medium supplemented with $10 \%$ fetal bovine serum (FBS), and examined weekly by optical microscopy for 1 month in search of promastigote forms of the parasite [15]. Confirmation of infection and characterization of the parasite as $L$. infantum was performed using qPCR with specific species primers [16]. After DNA extraction, the sample was amplified using the TaqMan ${ }^{\circledR}$ system on the StepOne platform $^{\text {TM }}$ (Applied Biosystems ${ }^{\circledR}$, Thermo Fisher Scientific, Waltham, MA, USA). The primers LEISH-1 (5'AACTTTTCTGGTCCTCCGGGTAG-3') and LEISH-2 (5'-ACCCCCAGTTTCCCGCC-3') and the probe TaqMan-MGB (FAM-5'AAAAATGGGTGCAGAAAT $-3^{\prime}-\mathrm{NFQM}-3 \mathrm{~GB}$ ) were used in the qPCR, targeting a conserved region of the $L$. infantum kinetoplast DNA. The samples were amplified on the StepOne ${ }^{\mathrm{TM}}$ platform. After confirmation of infection by all proposed methodologies $\left(\mathrm{DPP}^{\circledR}, \mathrm{qPCR}\right.$ and parasitological culture), the treatment was started.

The entire treatment was based on recommendations in the LeishVet canine leishmaniasis treatment manual [17]. Monotherapy with miltefosine was carried out according to the manufacturer's instructions as two treatment courses with an interval of 4 months between treatments. In each treatment course, a daily dose of $2 \mathrm{mg} / \mathrm{kg}$ of the drug was administered for 28 consecutive days. In combination therapy, miltefosine was combined allopurinol that was given in two daily doses $(10 \mathrm{mg} / \mathrm{kg} /$ day) during the entire treatment period, including during the 4-month interval between the two miltefosine treatments. New parasite collections were performed immediately before the start of the new course with the aim to isolate parasites in addition to those isolated prior to commencement of treatment with miltefosine (T0) and after one (T1) and two (T2) courses of miltefosine treatment. The commercial drugs milteforan ${ }^{\mathrm{TM}}$ (Virbac $^{\circledR}$ ), amphotericin B (generic pharmacy) and meglumine antimoniate (generic pharmacy) were used for the in vitro assays as a source of miltefosine, amphotericin B and meglumine antimoniate, respectively. The trivalent form of meglumine antimoniate (antimony potassium tartrate trihydrate; Sigma ${ }^{\circledR}$, Sigma-Aldrich, St. Louis, MO, USA) was used in the promastigote tests against antimony. The drugs were stored as indicated on their package inserts and diluted immediately before the assays in Schneider's culture medium until the desired concentrations were reached.

The half maximal inhibitory concentration $\left(\mathrm{IC}_{50}\right)$ values against T0, T1 and T2 parasites and L. infantum reference strain MHOM/BR/74/PP75 promastigote forms were determined using the MTT [3-(4,5-dimethylthiazol-2-yl)-2,5-diphenyltetrazolium bromide] colorimetric assay [18]. A control (no drugs added) was used for each isolate. The $\mathrm{IC}_{50}$ values were obtained using cell viability values for each drug. For assays against the amastigote forms of the isolates and the reference strain, the THP-1 
human leukemia monocytic cell line, was used as a host. The monocytes were kept at $37{ }^{\circ} \mathrm{C}$ in a humid incubator, under an atmosphere of $5 \% \mathrm{CO}_{2}$, in RPMI 1640 medium supplemented with $10 \%$ FBS, HEPES, and $1 \%$ antibiotic (penicillin streptomycin; Sigma ${ }^{\circledR}$, Sigma-Aldrich). Cultures were maintained weekly until their growth reached $1 \times 10^{6}$ cells $/ \mathrm{ml}$. Thereafter, THP- 1 cells were seeded in 96-well plates at a density of $5 \times 10^{4}$ cells/well in RPMI 1640 medium containing $200 \mathrm{nM}$ phorbol myristate acetate (PMA). The plates were then incubated for $96 \mathrm{~h}$ to allow cell differentiation into adhered macrophages, with the culture medium replaced with new culture medium without PMA after $48 \mathrm{~h}$. Concomitantly, the isolates and the reference strain of $L$. infantum were cultured up to 6-7 days in order to be able to inoculate cells already adhered and differentiated into macrophages. Inoculation was carried out at the ratio of 10 parasites per cell (10:1), and the wells containing the differentiated cells incubated for $4 \mathrm{~h}$. The different drug concentrations were then added (in triplicate per evaluated dose) to each well and the plates were incubated for a further $48 \mathrm{~h}$. After treatment, the cells were fixed with methanol and stained with DAPI to enable the intracellular amastigote count. A negative control (without treatment) was used as a $100 \%$ infection. Inhibitory activity was assessed by counting the number of intracellular amastigotes in 100 cells randomly captured from each well $(\times 40$ objective). Values were expressed as percentage of inhibition $(\mathrm{PI})=100-[(T \times 100) / C]$, where $T$ represents the average number of amastigotes treated and $C$ is the average number of amastigotes from the negative control [19]. The $\mathrm{IC}_{50}$ values were determined using PI values for each concentration of each drug. To measure the growth curve, a culture containing the isolates and the reference strain in exponential growth phase was adjusted to the concentration of $1 \times 10^{6}$ parasites $/ \mathrm{ml}$ and seeded in a 24 -well plate $(1 \mathrm{ml}$ per well). The absorbance values were measured at $800 \mathrm{~nm}$ every $24 \mathrm{~h}$ for 8 days to correlate the increase in absorbance with the concentration of parasites in the culture [20]. For determination of the infectivity rates, THP-1 cells were infected with the isolates and the reference strain as previously described. After the fixing, staining and counting of 100 cells, the average number of amastigotes per cell infected with the isolates and with the reference strain were compared. The metacyclogenesis rates were determined by the negative selection methodology with peanut agglutinin (PNA) (Sigma ${ }^{\circledR}$, Sigma-Aldrich) [21, 22]. Briefly, 6- to 7-day-old cultures of the isolates and the reference strain were collected by centrifugation $(2000 \mathrm{~g}, 10 \mathrm{~min})$ and resuspended at a concentration of $2 \times 10^{8}$ parasites $/ \mathrm{ml}$ in $10 \mathrm{ml}$ of Schneider's medium supplemented with $50 \mu \mathrm{g} / \mathrm{ml}$ PNA. The promastigotes were left at room temperature for $30 \mathrm{~min}$ for agglutination, following which the supernatant and the pellet were immediately collected. The pellet was resuspended once again in $10 \mathrm{ml}$ Schneider's medium supplemented with $50 \mu \mathrm{g} / \mathrm{ml}$ PNA, and both the pellet and supernatant were collected by centrifugation $(200 \mathrm{~g}$, $10 \mathrm{~min}$ ). The supernatant resulting from both collections was centrifuged $(2000 \mathrm{~g}, 10 \mathrm{~min})$ to obtain the metacyclic promastigotes. The number of metacyclic promastigotes was determined by counting in a Neubauer chamber and the percentage of metacyclogenesis among the isolates was calculated by the ratio of the number of metacyclic promastigotes to the total initial promastigote population. All experiments were carried out in triplicate.

Data normality was assessed by a KolmogorovSmirnov test, and the $\mathrm{IC}_{50}$ values was obtained with PRISM version 5 software (GraphPad Software, San Diego, CA, USA) using non-linear regression. All groups were compared using parametric one-way analysis of variance, followed by the Tukey test.

The species-specific primers used in the qPCR successfully confirmed infection by $L$. infantum, and the parasite was isolated in culture. All tests were repeated immediately before the start of a new treatment course, resulting in three different isolates: MCAN/BR/19/CG06T0 (T0), MCAN/BR/19/CG06T1 (T1) and MCAN/BR/20/ CG06T2 (T2), which enabled access to the parasites at different stages throughout the dog's treatment with miltefosine plus allopurinol.

Susceptibility assays conducted with the isolates and the reference strain showed a significant increase in the $\mathrm{IC}_{50}$ values of the promastigote (Fig. 1a, c) $\left(F_{(3,8)}=30.11\right.$, $P=0.0001)$ and amastigote (Fig. $1 \mathrm{~b}, \mathrm{~d})\left(F_{(3,8)}=27.56\right.$, $P=0.0001$ ) forms, which is evidence of resistance to miltefosine and amphotericin $B$ increasing with increasing number of treatment courses. The parasites isolated prior to treatment (T0) presented $\mathrm{IC}_{50}$ values against miltefosine equal to those of the control; however, these values increased after only one course of treatment (T1) (Fig. 1a, b), diverging statistically from those of the reference strain. The upward trend continued throughout the treatment, with $\mathrm{T} 2$ isolates presenting $\mathrm{IC}_{50}$ values approximately twofold higher than those of the reference strain.

The same pattern was observed in the parasites treated with amphotericin $B$, where an increase in resistance to the drug was verified throughout the treatment courses (Fig. 1c, d). In the promastigote forms of the parasites (Fig. 1c), the $\mathrm{IC}_{50}$ values of the isolates before the dog's treatment with miltefosine plus allopurinol (T0) was already higher than that of the reference strain $\left(F_{(3,}\right.$, $\left.\left.{ }_{8}\right)=17.74, P=0.0007\right)$; this was also observed at T1 in the assays with amastigote forms (Fig. 1d) $\left(F_{(3,8)}=25.96\right.$, $P=0.0002)$. No statistical difference was found between 

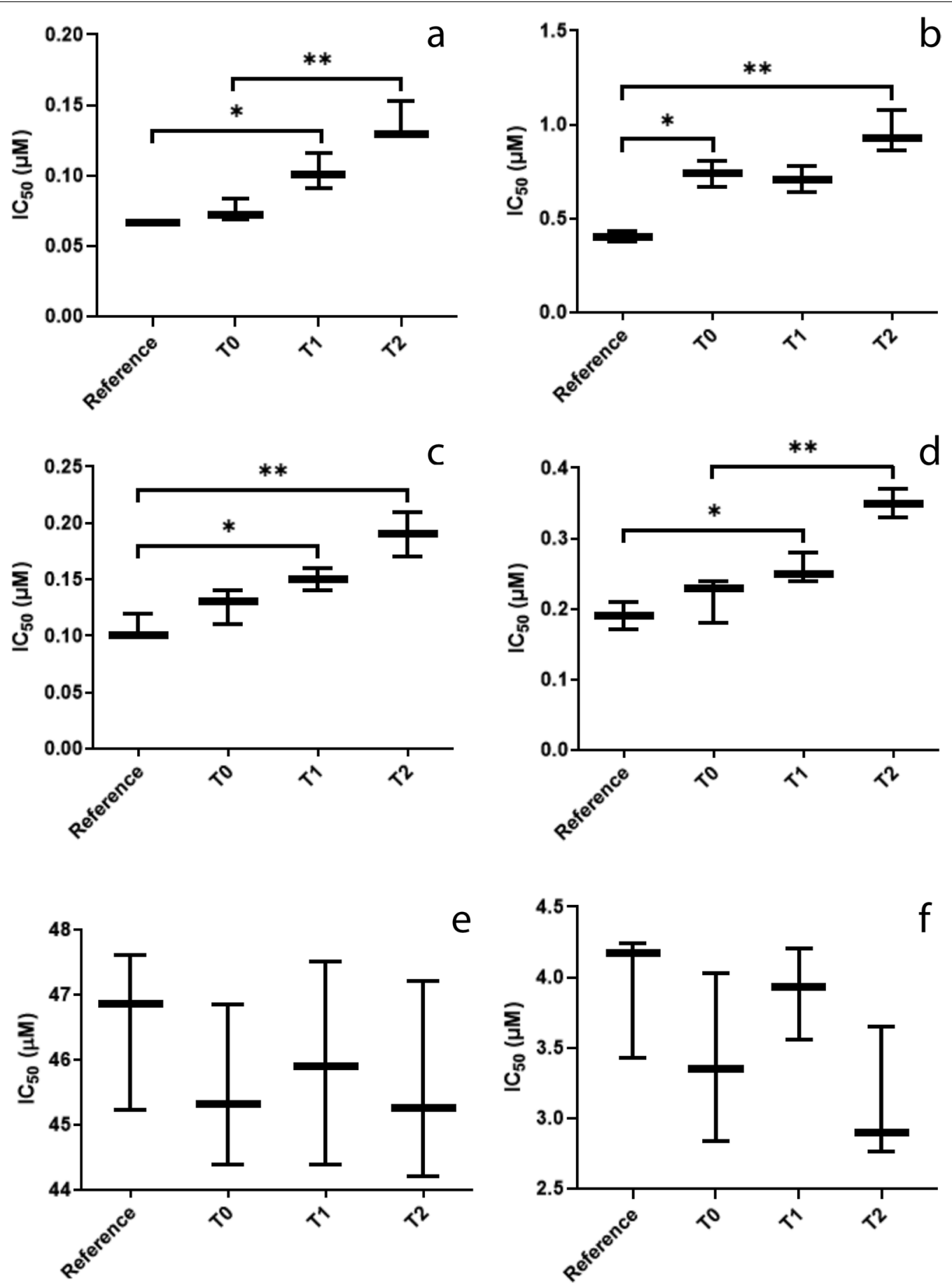

Fig. 1 Boxplot of results of the in vitro resistance tests of Leishmania infantum isolates and L. infantum reference strain MHOM/BR/74/PP75 to the drugs tested. $\mathbf{a}, \mathbf{b} \mid C_{50}$ values of the promastigote (a) and amastigote $(\mathbf{b})$ forms of the isolates and reference strain against miltefosine. $\mathbf{c}, \mathbf{d} I C_{50}$ values of promastigote (c) and amastigote (d) forms of the isolates and reference strain against amphotericin B. e, $\mathbf{f} \mid C_{50}$ values of promastigote (e) and amastigote (f) forms of the isolates and reference strain against meglumine antimoniate. Asterisks indicate statistical significance at ${ }^{*} P<0.05$ and ${ }^{*} P<0.01$. Abbreviations: $I_{50}$, Half maximal inhibitory concentration; T0, prior to commencement of treatment with miltefosine; T1, T2, after 1 and 2 courses of miltefosine treatment, respectively 
the $\mathrm{IC}_{50}$ values of the $\mathrm{T} 0, \mathrm{~T} 1$, and $\mathrm{T} 2$ isolates against meglumine antimoniate.

Results of the growth curve of the isolates in culture medium showed no difference between the number of parasites or cell proliferation rate. The infectivity rate was higher in the reference strain (Fig. 2). The cells infected with the reference strain had an average of six amastigotes per cell, which was more than the number in T0 $(<4$ amastigotes per cell) and T1 and T2 (both with $<2$ amastigotes per cell) isolates $\left(F_{(3,8)}=54.76, P<0.0001\right)$.

The metacyclogenesis rates showed a clear upward trend with increasing treatment, although the differences were not statistically significant. Parasite samples isolated from the dog before treatment with miltefosine plus allopurinol showed an average of $2 \times 10^{4}$ parasites $/ \mathrm{ml}$. After one course of treatment, this number increased to about $3 \times 10^{4}$ parasites $/ \mathrm{ml}$, ultimately reaching approximately $5 \times 10^{4}$ parasites $/ \mathrm{ml}$ after two treatment courses.

A strong linear correlation $\left(R^{2}=0.87\right)$ was observed between the number of treatment courses with miltefosine plus allopurinol to which the dog was subjected and the increase in the $\mathrm{IC}_{50}$ values of $L$. infantum isolates against miltefosine. One explanation of these results is that the treatment of dogs with miltefosine is not effective in achieving a complete elimination of the parasites [5-7]. Those parasites that remain in the dog are exposed to subtherapeutic doses, resulting from the long halflife of this drug [23], which drive a selection of resistant parasites.

There is general consensus that most dogs treated with miltefosine respond well to treatment, with the parasite load greatly reduced for periods longer than 4 months [5]. However, in a minority of cases, the treatment is not successful, and the dog becomes a favorable environment

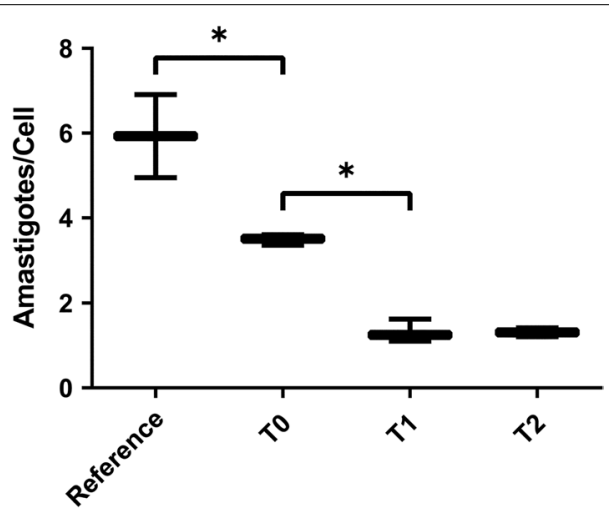

Fig. 2 Boxplot of average number of amastigotes per THP-1 cell infected with the L. infantum reference strain (MHOM/BR/74/PP75), parasites isolated from the dog before treatment (T0), after 1 course of treatment (T1) and after 2 courses of treatment (T2). Asterisk indicates statistical significance at ${ }^{*} P<0.05$ for the emergence of resistant parasites, as observed in the present study. It is well established that the therapeutic success of the treatment and the clinical course of the disease are closely linked to the profile of the dog's immune response [25]. Dogs that have a Th1-polarized immune response have a better prognosis than those that have a Th2 immune response. A humoral response profile (Th2) is not efficacious in combating the intracellular parasite, which leads to the need for successive therapeutic rounds with the drug, thereby facilitating the emergence of resistance.

Studies have also shown that resistance to miltefosine remains constant even after passage through sand flies [26] and successive in vitro passages [24].This finding, combined with the use of miltefosine therapy to treat CanL in endemic areas and intense zoonotic transmission, and coupled with the knowledge that the dog can be a source of vector infection for $L$. infantum even weeks after the end of treatment, despite being clinically cured [8], may aggravate the problem involving the emergence of resistant parasites, since the dog can become infected with parasites that have already come into contact with the drug and, consequently, already present high resistance to it. As such, it is fundamental that not only uninfected dogs but also infected dogs under treatment are protected through the use of insecticides and repellents [17].

The isolates analyzed showed the acquisition of resistance not only to one of the drugs they had contact with during the treatment of the dog (miltefosine), but also to amphotericin B. This phenomenon, called cross-resistance, is well established in species of the genus Leishmania and involves several drugs [27-29]. Mondelaers et al. [27] reported clear cross-resistance between miltefosine and amphotericin B, corroborating the findings of the present study. In our analyses, a strong linear correlation $\left(R^{2}=0.83\right)$ was observed between the number of treatment courses with miltefosine plus allopurinol and the increase in the $\mathrm{IC}_{50}$ values of $L$. infantum isolates against amphotericin $B$. Acquisition of resistance to amphotericin B was similar to that to miltefosine, with $\mathrm{IC}_{50}$ values already higher at $\mathrm{T} 1$ than at $\mathrm{T} 0$, reaching values about of 1.8-fold higher than those at T0 after two courses of treatment with miltefosine (T2).

The possible cross-resistance between miltefosine and amphotericin $B$ is a concern, since amphotericin $\mathrm{B}$ is one of the most commonly used drugs to treat VL in humans. Thus, parasites resistant to both drugs could be transmitted to other dogs and, eventually, to humans, also considering that resistance is maintained even after passage through sand flies [26]. Amphotericin B, in its liposomal formulation, is used to treat VL in pregnant women, children aged < 
1 year, individuals aged $>50$ years, those with comorbidities and those who are HIV positive [30]. All of of these groups are considered at risk for the disease and require less toxic and a more effective treatment. The effectiveness of amphotericin $B$ can be reduced by the emergence of parasites resistant to the drug.

Additionally, allopurinol (used in combination with miltefosine in the dog treated herein) is a leishmaniostatic drug [31,32]. There is a previous report of cross-resistance between meglumine antimoniate and allopurinol, but not between these drugs and miltefosine or amphotericin B [28]. These data suggest that the increased resistance of the parasites to amphotericin $B$ and miltefosine observed in our study is due to the contact of the parasites with miltefosine-and not allopurinol; however, further research is required.

There did not appear to be any significant changes in the parasite fitness parameters associated with the acquisition of resistance. While some studies demonstrate that the acquisition of resistance is followed by increased rates of infectivity, proliferation and metacyclogenesis [12], other studies point out that the parasite shows a decrease in some of these parameters in exchange for resistance, in a type of metabolic exchange currency [13, 26]. In our study, the metacyclogenesis rates showed an upward trend that corresponded with an increasing number of treatment courses with miltefosine plus allopurinol; however, the trend was not statistically significant. Some authors consider the metacyclogenesis rate to be one of the most important parameters that determine the virulence of a strain [14], since a larger number of parasite infective forms in the vectors may favor the establishment of the infection in the vertebrate host [33].

In conclusion, the data obtained in this study indicate increased $L$. infantum resistance to miltefosine and amphotericin B after the treatment of a dog with miltefosine plus allopurinol. Considering that we used strains isolated from a single dog, further studies are needed to better understand the impact of treating dogs with miltefosine (alone or in combination with allopurinol) on the emergence of resistant strains. Ideally, these studies should include a larger number of $L$. infantum strains isolated from dogs, with varied immune response profiles and submitted to different treatment regimes.

\section{Abbreviations}

CanL: Canine leishmaniasis; VL: Visceral leishmaniasis.

\section{Acknowledgements}

We thank the Carlos Chagas Institute (FIOCRUZ Paraná) for use of its facilities and technological platforms.

\section{Authors' contributions}

GG, MPC and ASG were responsible for the collection of samples from the dog in the field. The in vitro tests were developed by GG. FBF and LCSM provided technical support and scientific consultancy. All authors read and approved the final manuscript.

\section{Funding}

This study was funded by Conselho Nacional de Pesquisa e Desenvolvimento (CNPq) by the Grant for Productivity in Research (309862/2015-9) and Professional Education Expansion Program (Proep; Grant no. 442055/2019-6). This study also was supported by Instituto Carlos Chagas and Fundação Oswaldo Cruz (FIOCRUZ). The funders played no role in the decision to publish nor in the preparation of the manuscript.

Availability of data and materials

Not applicable.

\section{Declarations}

\section{Ethics approval and consent to participate}

The study was approved by the Ethics Committee on Animal Use of FIOCRUZ under protocol no. LW-14/21.

\section{Consent for publication}

Not applicable.

\section{Competing interests}

The authors declare that they have no competing interests.

\section{Author details}

${ }^{1}$ Cell Biology Laboratory, Carlos Chagas Institute, Oswaldo Cruz Foundation (FIOCRUZ), Curitiba, Paraná 81310-020, Brazil. 2Private Practice, Campo Grande, Brazil.

Received: 11 August 2021 Accepted: 17 November 2021

Published online: 09 December 2021

\section{References}

1. Dantas-Torres F. Canine leishmaniosis in South America. Parasit Vectors. 2009;2(Suppl 1):S1.

2. Departamento de vigilância epidemiológica, Secretaria de Vigilância em Saúde, Ministério da Saúde (BR). Guia de Vigilância em Saúde. 3rd ed. Brasilia: Ministério da Saúde (BR). 2019.

3. Werneck GL. Visceral leishmaniasis in Brazil: rationale and concerns related to reservoir control. Rev Saude Publica. 2014:48:851-5.

4. Ministério da Agricultura, Pecuária e Abastecimento e Ministério da Saúde. Nota técnica conjunta no. 001/2016. https://www.sbmt.org.br/ portal/wp-content/uploads/2016/09/nota-tecnica.pdf. Accessed $18 \mathrm{Sep}$ 2021.

5. dos Santos NF, Avino VC, Galvis-Ovallos F, Pereira-Chioccola VL, Moreira $M A B$, Romariz APPL, et al. Use of miltefosine to treat canine visceral leishmaniasis caused by Leishmania infantum in Brazil. Parasit Vectors. 2019;12:79.

6. Manna L, Corso R, Galiero G, Cerrone A, Muzj P, Gravino AE. Long-term follow-up of dogs with leishmaniosis treated with meglumine antimoniate plus allopurinol versus miltefosine plus allopurinol. Parasit Vectors. 2015;8:289.

7. Andrade HM, Toledo VPCP, Pinheiro MB, Guimarães TMPD, Oliveira NC, Castro JA, et al. Evaluation of miltefosine for the treatment of dogs naturally infected with L. infantum (=L. chagasi) in Brazil. Vet Parasitol. 2011;181:83-90.

8. Chappuis F, Sundar S, Hailu A, Ghalib H, Rijal S, Peeling RW, et al. Visceral leishmaniasis: what are the needs for diagnosis, treatment and control? Nat Rev Microbiol. 2007;5:873-82.

9. Sereno D, Cavaleyra M, Zemzoumi K, Maquaire S, Ouaissi A. Axenically grown amastigotes of Leishmania infantum used as an in vitro model to investigate the pentavalent antimony mode of action. Antimicrob Agents Chemother. 1998;42:3097-102.

10. Kumar D, Kulshrestha A, Singh R, Salotra P. In vitro susceptibility of field isolates of Leishmania donovani to miltefosine and amphotericin B: correlation with sodium antimony gluconate susceptibility and implications 
for treatment in areas of endemicity. Antimicrob Agents Chemother. 2009;53:835-8.

11. Eberhardt $E$, Bulté $D$, van Bockstal $L$, van den Kerkhof $M, \operatorname{Cos} P$, Delputte $P$, et al. Miltefosine enhances the fitness of a non-virulent drug-resistant Leishmania infantum strain. J Antimicrob Chemother. 2019;74:395-406.

12. Deep DK, Singh R, Bhandari V, Verma A, Sharma V, Wajid S, et al. Increased miltefosine tolerance in clinical isolates of Leishmania donovani is associated with reduced drug accumulation, increased infectivity and resistance to oxidative stress. PLoS Negl Trop Dis. 2017;11:e005641.

13. Rai K, Cuypers B, Bhattarai NR, Uranw S, Berg M, Ostyn B, et al. Relapse after treatment with miltefosine for visceral leishmaniasis is associated with increased infectivity of the infecting Leishmania donovani strain. MBio. 2013:4:11-3.

14. da Silva R, Sacks LD. Metacyclogenesis is a major determinant of Leishmania promastigote virulence and attenuation. Infect Immun. 1987;55:2802-6.

15. Abrantes TR, de Madeira MF, da Silva DA, dos Carolina Perié SFS, Mendes Junior AA, Menezes RC, et al. Identification of canine visceral leishmaniasis in a previously unaffected area by conventional diagnostic techniques and cell-block fixation. Rev Inst Med Trop Sao Paulo. 2016;58:3.

16. Campo MP, Madeira MF, Silva DA, Solcà MS, Espíndola OM, Mendes Junior $A A V$, et al. Accuracy of quantitative polymerase chain reaction in samples of frozen and paraffin-embedded healthy skin for the diagnosis of canine visceral leishmaniasis. Arq Bras Med Vet Zootec. 2017;69:1443-50.

17. LeishVet. Therapy for canine leishmaniosis. https://www.leishvet.org/factsheet/therapy/. Accessed 16 Nov 2021.

18. van Meerloo J, Kaspers GJL, Cloos J. Cell sensitivity assays: the MTT assay. Methods Mol Biol. 2011;731:237-45.

19. Donega M, Mello S, Moraes R, Jain S, Tekwani B, Cantrell C. Pharmacological activities of Cilantro's aliphatic aldehydes against Leishmania donovani. Planta Med. 2014;80:1706-11.

20. Ouellette M, Fase-Fowler F, Borst P. The amplified $\mathrm{H}$ circle of methotrexate-resistant Leishmania tarentolae contains a novel P-glycoprotein gene. EMBO J. 1990;9:1027-33.

21. Sacks DL, Hieny S, Sher A. Identification of cell surface carbohydrate and antigenic changes between noninfective and infective developmental stages of Leishmania major promastigotes. J Immunol. 1985;135:564-9.

22. Alcolea PJ, Alonso A, Degayón MA, Moreno-Paz M, Jiménez M, Molina R, et al. In vitro infectivity and differential gene expression of Leishmania infantum metacyclic promastigotes: negative selection with peanut agglutinin in culture versus isolation from the stomodeal valve of Phlebotomus perniciosus. BMC Genomics. 2016:17:375-89.

23. Maltezou HC. Drug resistance in visceral leishmaniasis. J Biomed Biotechnol. 2010;2010:617521.

24. Carrió J, Portús M. In vitro susceptibility to pentavalent antimony in Leishmania infantum strains is not modified during in vitro or in vivo passages but is modified after host treatment with meglumine antimoniate. BMC Pharmacol. 2002;2:11.

25. Giunchetti RC, Silveira P, Resende LA, Leite JC, de Melo-Júnior OAO, Rodrigues-Alves ML, et al. Canine visceral leishmaniasis biomarkers and their employment in vaccines. Vet Parasitol. 2019;271:87-97.

26. van Bockstal L, Bulté D, Hendrickx S, Sadlova J, Volf P, Maes L, et al. Impact of clinically acquired miltefosine resistance by Leishmania infantum on mouse and sand fly infection. Int J Parasitol Drugs Drug Resist. 2020;13:16-21.

27. Mondelaers A, Hendrickx S, van Bockstal L, Maes L, Caljon G. Miltefosineresistant Leishmania infantum strains with an impaired MT/ROS3 transporter complex retain amphotericin B susceptibility. J Antimicrob Chemother. 2018;73:392-4.

28. Gómez Pérez V, García-Hernandez R, Corpas-López V, Tomás AM, MartínSanchez J, Castanys S, et al. Decreased antimony uptake and overexpression of genes of thiol metabolism are associated with drug resistance in a canine isolate of Leishmania infantum. Int J Parasitol Drugs Drug Resist. 2016;6:133-9.

29. Maia C, Nunes M, Marques M, Henriques S, Rolão N, Campino L. In vitro drug susceptibility of Leishmania infantum isolated from humans and dogs. Exp Parasitol. 2013;135:36-41.

30. Ministério da saúde (BR). Nota Técnica No. 232/2013. https://www.gov. br/saude/pt-br/composicao/conjur/demandas-judiciais/notas-tecnicas/ notas-tecnicas-medicamentos/notas-tecnicas/a/anfotericina-b-atual izado-em-04-12-2015.pdf/view. Accessed 18 Sep 2021.
31. Kamau SW, Nunez R, Grimm F. Flow cytometry analysis of the effect of allopurinol and the dinitroaniline compound (Chloralin) on the viability and proliferation of Leishmania infantum promastigotes. BMC Pharmacol. 2001;1:1.

32. Dias de ÁFLR, Ayresda ECBS, de Oliveira Martins DT, Maruyama FH, de Oliveira RG, de Carvalho MR, et al. Comparative study of the use of miltefosine, miltefosine plus allopurinol, and allopurinol in dogs with visceral leishmaniasis. Exp Parasitol. 2020;217:107947.

33. Doehl JSP, Bright Z, Dey S, Davies H, Magson J, Brown N, et al. Skin parasite landscape determines host infectiousness in visceral leishmaniasis. Nat Commun. 2017;8:57.

\section{Publisher's Note}

Springer Nature remains neutral with regard to jurisdictional claims in published maps and institutional affiliations.

Ready to submit your research? Choose BMC and benefit from:

- fast, convenient online submission

- thorough peer review by experienced researchers in your field

- rapid publication on acceptance

- support for research data, including large and complex data types

- gold Open Access which fosters wider collaboration and increased citations

- maximum visibility for your research: over $100 \mathrm{M}$ website views per year

At BMC, research is always in progress.

Learn more biomedcentral.com/submissions 